\title{
EXPERIMENTS ON THE GROWTH OF SPONGY ICE NEAR A STAGNANT POINT
}

\author{
By G.S.H. LOCK and I.B. Foster
}

(Department of Mechanical Engineering, University of Alberta, Edmonton, Alberta T6G 2G8, Canada)

\begin{abstract}
The paper presents experimental observations on the growth of spongy ice in the vicinity of the forward stagnation point of a disc situated in a cross flow containing supercooled water droplets. Following some preliminary observations, the discussion focuses on two quantities: the ice fraction and the rate of growth of the accretion. The data presented reveal the effects of air speed, air temperature, liquid-water content, and salinity. They also suggest two morphological regimes: at higher air temperatures, the growth appeared to be crystalline columnar; at lower temperatures, smaller crystals appeared to be randomly distributed, producing a mushy accretion.
\end{abstract}

\section{NOMENCLATURE}

$\begin{array}{ll}a, b, c, d & \text { Constants } \\ c_{\mathrm{p}} & \text { Specific heat } \\ f & \text { Fraction } \\ h & \text { Heat-transfer coefficient } \\ I & \text { Ice fraction } \\ \text { Ste } & \text { Stefan number } \\ l & \text { Time } \\ T & \text { Temperature } \\ U & \text { Air velocity } \\ w & \text { Liquid-water content } \\ x & \text { Accretion thickness } \\ \rho & \text { Density } \\ \lambda & \text { Latent heat of fusion } \\ \theta & \text { Temperature difference }\end{array}$

\section{Subscripts}

w

a

Superscript

$$
\begin{aligned}
& \text { Ice } \\
& \text { Water } \\
& \text { Shed } \\
& \text { Air }
\end{aligned}
$$

\section{Average}

\section{INTRODUCTION}

The existence of spongy ice - an ice matrix containing interstitial water - has been known for some time. Early interest centred around the description of hailstone growth (Fraser and others, 1952; List, 1959; Macklin, 1961; Brownscombe and Hallett, 1967; Knight, 1968; Knight and Knight, 1968a, b). Since then, interest has expanded to include spongy accretion on such structures as ships and artificial islands (Gates and others, 1986; Makkonen, 1987; Szilder and Lozowski, 1989). Surprisingly, no observations of spongy ice on inland structures appear to have been reported in the literature, even though the necessary conditions for its existence undoubtedly exist.

The conventional explanation of sponginess is rooted in the idea that the ice surface is continually deluged by supercooled water droplets which create a supercooled water film. Under these conditions, the ice is believed to grow essentially along the $a$-axes, with dendrites penetrating the water film in such a fashion, and at such a rate, as to trap unfrozen, interdendritic water. This situation is not unlike dendritic growth in the presence of constitutional supercooling when the interdendritic water contains concentrated solutes (Knight, 1968).

In this model of spongy accretion, growth occurs over a nominal surface containing the dendrite tips. Behind the surface, ice and water must be in thermodynamic equilibrium at the equilibrium freezing temperature. According to measurements of $a$-axis growth in supercooled water (Macklin and Ryan, 1965; Pruppacher, 1967; Lindenmeyer, unpublished), tip velocities will be very high; indeed, they are likely to be much higher than reported accretion-growth velocities which are, at most, of the order of $1 \mathrm{~cm} \mathrm{~min}^{-1}$ (Knight, 1968). The actual growth process must therefore be modified in some way, such as by dendrite breakage, or it must incorporate a different mechanism.

At temperatures substantially below the equilibrium freezing temperature, nucleation may occur spontaneously, and, if so, growth would no longer be limited to a surficia region occupied by dendrite tips. This possibility would lead to a uniform distribution of ice embryos on the outer (windward) surface of the supercooled film which, having some thickness, might be more accurately described as an accretion zone. On the inner surface of this zone, the ice-water composite must reach a final steady state which, if heat is not conducted into the substrate, corresponds to stable equilibrium. Between the bounding surfaces of the accretion zone, crystals grow into water whose local temperature varies between the droplet impact temperature and the equilibrium freezing temperature. This distributed model, in which crystal growth is closer to being isotropic, has characteristics which differ from those of the surficial model where crystal orientation is more significant.

This paper is an attempt to explore the above growth models of spongy accretion. It consists of an experimental study of growth in the vicinity of the forward stagnation point on a disc situated on the end of a cylinder lying parallel to the air stream in which it is located. Measurements of growth velocity and ice fraction have been taken for a wide range of air velocities and temperatures representative of field conditions. Likewise, liquid-water contents have been chosen to be representative of wet accretion.

\section{THE EXPERIMENTS}

\section{Experimental arrangements}

The experiments were conducted in the Marine Icing Wind Tunnel facility in the Department of Mechanical Engineering, University of Alberta (Foy, unpublished). This is a vertical tunnel (see Fig. 1) in which the air speed may be varied over a range of $0-25 \mathrm{~m} \mathrm{~s}^{-1}$ (here in a downward direction) and the air temperature may be set at any value between $-30^{\circ}$ and $0^{\circ} \mathrm{C}$. Up-stream of the test section is a 


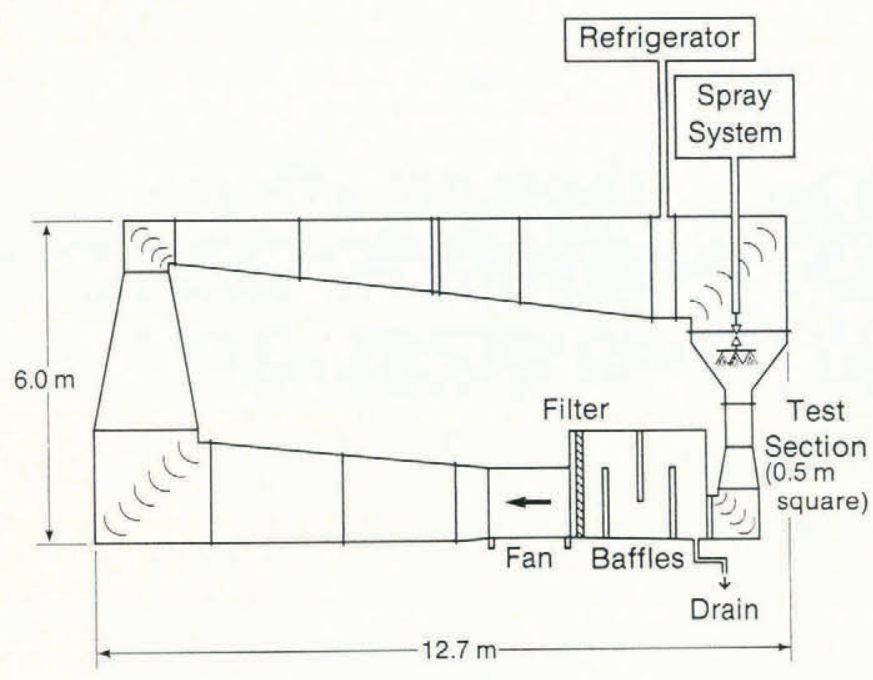

Fig. 1. Schematic of icing tunnel.

settling chamber in which the spray nozzles are located. The nozzle system and the refrigeration coils, placed even further up-stream, create a certain amount of turbulence which, by the time the air has reached the test section, has been reduced to an intensity of $2-3 \%$. Outside of a thin boundary layer, velocity and temperature are both uniform in the test section, which is $0.8 \mathrm{~m}$ long and $0.5 \mathrm{~m}$ square.

An array of spray nozzles creates a droplet flux which is neither monodisperse nor uniform in density, spatially. At low air speeds, the spray fills the entire test section, but as the air speed is increased, the spray coverage decreases. Experiments were therefore limited to a small region around the axis of the test section where the droplet flux was fairly uniform, e.g. $\pm 20 \%$ of the nominal value.

Preliminary experiments with a $2.0 \mathrm{~cm}$ diameter rotating cylinder in a cross flow (see Fig. 2a) revealed that the icing rate may be sensitive to the rotational speed, particularly near the zero speed. Rotation is an important feature of some forms of accretion, e.g. tumbling hailstones, but it is absent from many other forms, particularly those which
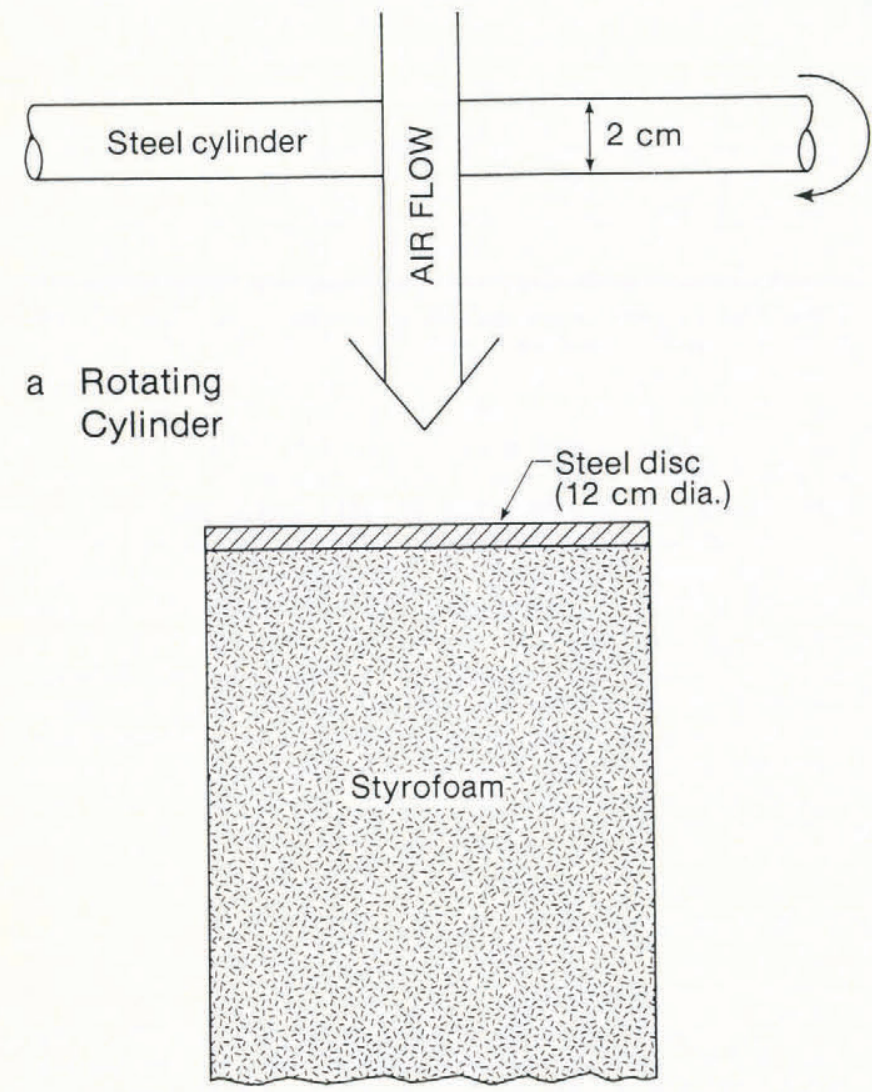

\section{b Stationary Disc}

Fig. 2. Arrangement of test specimens in air stream. a. Rotating cylinder; b. Stationary disc. occur on engineering structures. It was therefore decided to use a fixed test body under conditions which are common. Accordingly, a $12 \mathrm{~cm}$ diameter cylinder was placed parallel to the air direction and concentric with the tunnel axis (see Fig. 2b). This generated quasi-one-dimensional accretion under axisymmetric stagnation conditions, while creating a low tunnel-blockage ratio. Very little ice formed on the cylinder sides and no attempt was made to measure it.

A disc made from $6 \mathrm{~mm}$ thick steel sheet was mounted on the front of a $11 \mathrm{~cm}$ long styrofoam cylinder, thus limiting substrate conduction while preserving metallic characteristics during the initial phase of growth.

\section{Instrumentation}

The temperatures of the disc and the tunnel air were measured with thermocouples connected to a Fluke 2170A digital thermometer. Air speed was measured with a pitotstatic tube connected to a manometer. Interface growth rates were obtained by visually locating the interface height against a graduated scale for each of a series of times measured on a stop watch. Measurements of liquid-water content were obtained during each run using a Particle Measuring Systems optical array precipitation probe (OAP$260 \mathrm{X})$ connected to a Hewlett Packard 9000 digital computer via a Smart Probe controller (Foy, unpublished). Liquid-water contents were thus derived from the droplet distribution and count.

To determine the ice fraction of the spongy sample, defined by

$$
I=f_{\mathrm{i}} /\left(f_{\mathrm{i}}+f_{\mathrm{w}}\right)
$$

where $f_{\mathrm{i}}$ and $f_{\mathrm{w}}$ are the fractions of the incident water flux retained as ice and water, respectively, a calorimeter was built. This was based on the design of Blackmore (personal communication), and consisted of two thermally isolated chambers, one in which warm water is stored and one in which a charge of warm water is mixed with a sample of the accretion. A simple balance between the thermal energy lost by the water charge and that gained by the sample determines the mass of ice in the sample.

The calorimeter procedure was as follows. Warm $\left(35^{\circ} \mathrm{C}\right)$ water in a styrofoam cup was placed in the storage chamber and allowed to reach thermal equilibrium, at which point its temperature was measured accurately using a Fluke $2170 \mathrm{~A}$ digital thermometer and its mass determined with a Mettler PC 8000 balance. Upon addition of the ice sample $(30-50 \mathrm{~g})$, the cup was transferred to the other chamber where its new mass and final equilibrium temperature were subsequently measured. The mass of the water charge and ice sample, together with the initial and final temperatures, are all that are required to calculate the ice fraction, provided that the latent heat of fusion and specific heat capacity of the water are known; these were taken as $334 \times 10^{3} \mathrm{~kJ} \mathrm{~kg}^{-1}$ and $4.225 \times 10^{3} \mathrm{~kJ} \mathrm{~kg}^{-1} \mathrm{~K}^{-1}$, respectively.

To undertake experiments with salt water, the spraywater holding tank was charged with pure water to which sea salt was later added. By setting the salt content to $35 \%$, as measured by a Yellow Springs Instrument Company salinity meter, it was possible to simulate the growth of accretion from sea-water.

\section{Procedure and test schedule}

The data associated with each point in the air speedtemperature domain covered were obtained as follows. The air speed was first set nominally using a pitot-static tube. The refrigeration system and the spray system were then switched on, and the water-flow rate adjusted to give a liquid-water content and mean droplet radius in the required range. The desired air temperature was then set by means of a thermostat. While the system was cooling down to its final steady state, the substrate disc was protected with a plastic bag on which uncontrolled accretion was allowed to occur so that the disc itself was maintained at the equilibrium freezing temperature. Once the air temperature had stabilized in a range $\pm 0.3^{\circ} \mathrm{C}$ of the desired temperature, the test proper was begun by removal of the plastic bag, with the initial temperature of the substrate being very close to the equilibrium freezing temperature.

In addition to the air speed and temperature, readings of ice thickness were taken over a series of time intervals 
as described earlier. When sufficient time had elapsed to produce a substantial layer of ice, e.g. $2 \mathrm{~cm}$, the test was ended by stopping the flow of both air and water, a process which lasted less than $5 \mathrm{~s}$, after which a sample of ice was carefully cut (with a sharp, low-conductivity blade) from the centre of the accretion and transferred to the calorimeter. Over the short time period taken for the calorimetry to be completed, the tunnel conditions were re-set and the substrate restored to its initial ice-free state.

Tables I and II list the range of the two principal variables: air speed and temperature. As indicated, these offer a broad coverage of atmospheric conditions, but they exclude high, gusty winds and temperatures low enough to produce homogeneous nucleation. No attempt was made to vary the spray characteristics beyond making several changes in liquid-water content.

\section{RESULTS AND DISCUSSION}

\section{Preliminary observations}

As noted above, the experimental program was begun with an exploratory series designed partly to validate the technique and partly to establish the influence of rotational speed on the spongy accretion forming on a cylinder. The results of these early experiments are shown in Figure 3. Attempts to reproduce these data met only with qualitative success, thus focussing attention on the accuracy of the measuring technique. A formal error analysis revealed that the error in the ice fraction may be as large as $\pm 10 \%$ and was attributed largely to the method of cutting and collecting the ice sample. The technique was subsequently refined, as described earlier, thereby limiting the error to

\section{TABLE I. EXPERIMENTAL CONDITIONS (FRESH WATER)}

$\begin{array}{lccc}\text { Air speed } & \text { Air temperature } & \text { Water content } & 69 \\ & & & 70 \\ \mathrm{~m} \mathrm{~s}^{-1} & { }^{\circ} \mathrm{C} & \mathrm{g} \mathrm{m}^{-3} & 71 \\ & & & 72 \\ & & & 73 \\ 5 & -5 & 13 & 74 \\ 5 & -10 & 13 & 75 \\ 5 & -15 & 13 & 76 \\ 5 & -20 & 13 & 77 \\ 10 & -5 & 13 & 78 \\ 10 & -10 & 13 & 79 \\ 10 & -15 & 13 & 80 \\ 15 & -5 & 13 & 81 \\ 15 & -10 & 13 & 82 \\ 15 & -15 & 13 & 83 \\ 20 & -5 & 13 & 84 \\ 20 & -10 & 13 & 85 \\ 20 & -15 & 13 & 86 \\ 20 & -20 & 13 & 87 \\ 25 & -5 & 13 & 88 \\ 25 & -10 & 13 & 89 \\ 25 & -15 & 13 & 90 \\ 25 & -20 & 13 & 91 \\ 25 & -30 & 13 & 92\end{array}$

39

40

41

42

43

44

45

46

47

48

49

50

51

52

53

54

55

56

57

58

59

60

61

62

63
Test Air speed Air temperature

Water content

$$
\mathrm{m} \mathrm{s}^{-1}
$$

${ }^{\circ} \mathrm{C}$

$\mathrm{g} \mathrm{m}^{-3}$

5

-5
-10

-10
-15

$-20$

$-25$

$-5$

$-15$

$-20$

$-25$

$-5$

$-10$

$-15$

$-20$

$-25$

$-5$

$-10$

$-15$

$-5$

$-10$

$-15$

$-10$

$-15$

$-20$

$-5$

$-10$

$-15$

$-20$

-5
-10

$-15$

$-20$

$-5$

$-10$

$-15$

-20
-5

-5
-10

$-15$

$-20$

$-15$

$-25$

$-5$

$-10$

$-20$

$-30$

$-5$

$-15$

$-25$

$-5$

$-10$

$-20$

$-5$

$-15$

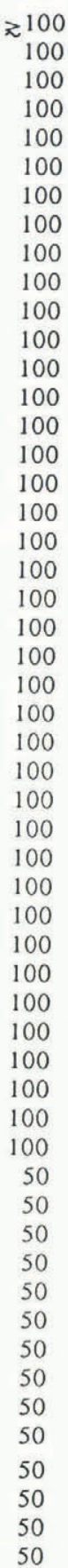

$\pm 5 \%$. Error bars shown in Figures 4 and 7 refer to the stationary disc experiments.

Despite the quality of the data in Figure 3 , it is evident that rotational speed exerts a significant, and evidently monotonic, effect on ice fraction. Since the ice fraction at higher speed is considerably less than that for a cylinder at rest, it was decided to avoid having to choose a meaningful speed, or speed range, until the physical model had been explored more fully at rest. Accordingly, a fixed stagnation flow was chosen and considered in detail. As a matter of convenience, the cylinder, which extended right across the tunnel, was replaced by a centrally located disc with a comparable blockage ratio and an axisymmetric flow pattern.

The assumption that the droplet velocity was roughly equal to the air velocity in the test section was checked against estimates of the time constant required for the 


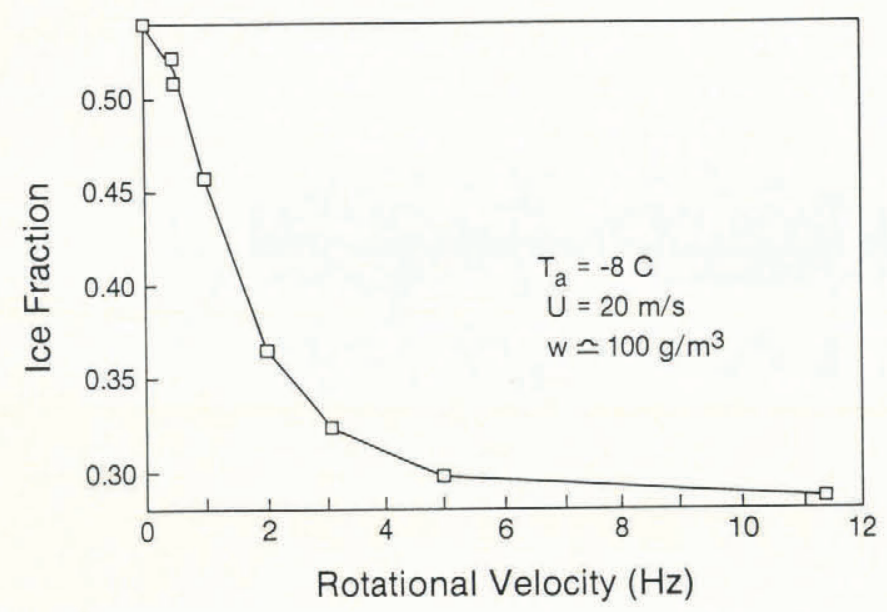

Fig. 3. Effect of rotation on accreted ice fraction.

attainment of "terminal" velocity between the spray bar and the test substrate. These estimates, together with the presence of an initial spray velocity, suggested that the assumption was correct.

\section{Fresh-water results}

Using the refined measuring technique, ice-fraction data for a fresh-water spray were obtained for various air speeds and temperatures. These are shown in Figure 4 with ice fraction $(I)$ plotted against air temperature $\left(T_{\mathrm{a}}\right)$. In Figure $4 \mathrm{a}$, the liquid-water content $(w)$ was maintained at $100( \pm 10) \mathrm{g} \mathrm{m}^{-3}$ for which the effect of air temperature is
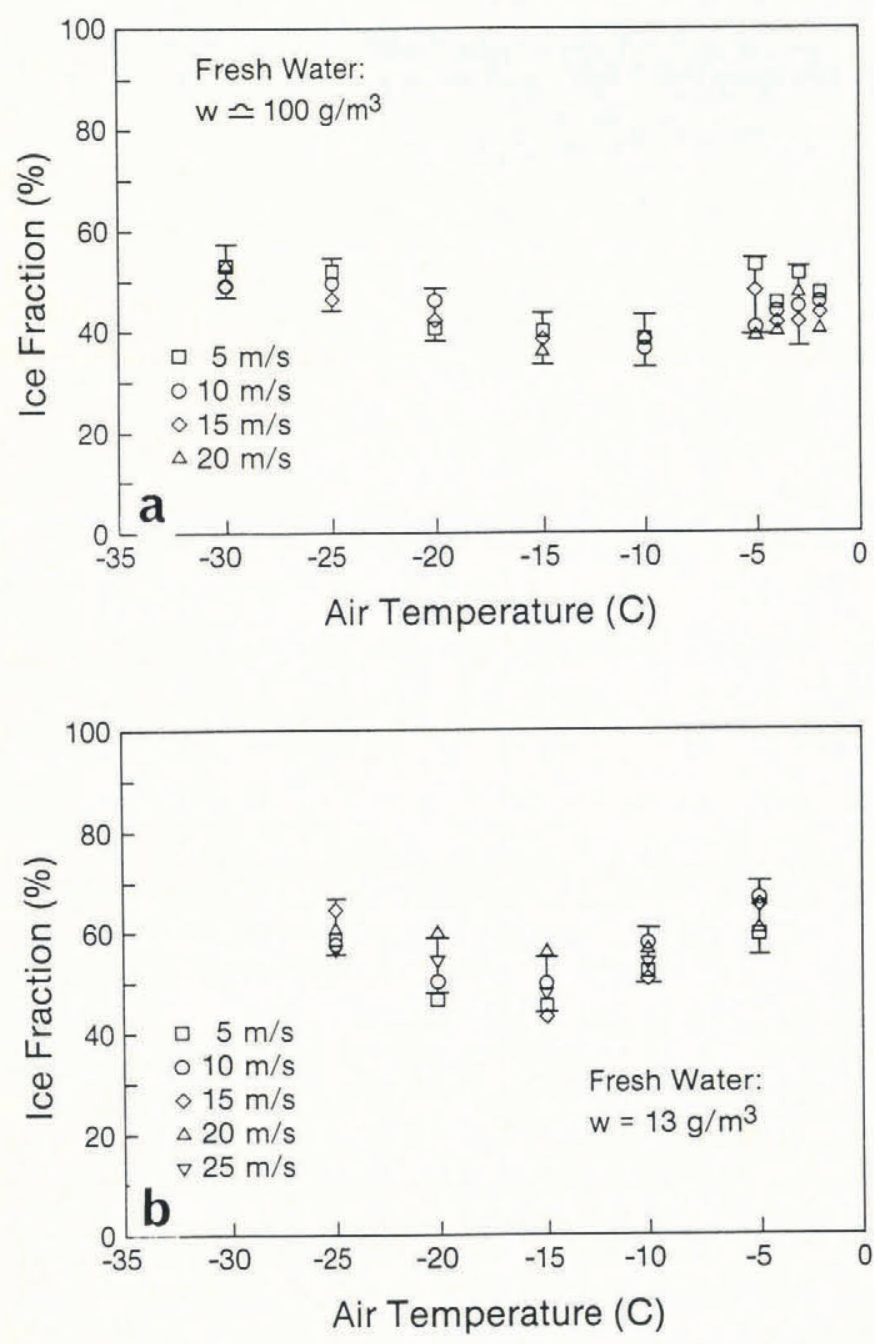

Fig. 4. Fresh-water ice fraction as a function of air temperature and speed. a. $\quad w=100 \mathrm{~g} \mathrm{~m}^{-3} ; \quad b$. $w=13 \mathrm{~g} \mathrm{~m}^{-3}$. seen to be quite small, consisting of a shallow minimum between $-15^{\circ}$ and $-10^{\circ} \mathrm{C}$. The data with $T_{\mathrm{a}}=-30^{\circ},-25^{\circ}$, $-20^{\circ}$, and $-15^{\circ} \mathrm{C}$, suggest that the slight rise in ice fraction accompanying lower temperatures may continue, but do not suggest a rising ice fraction for temperatures increasing above $-5^{\circ} \mathrm{C}$. The effect of air speed $(U)$ is equally small. As indicated, the variations are almost completely contained within the range of experimental uncertainty. Strictly, therefore, no air-speed effect can be distinguished, although it might be expected that, in general, the ice fraction would increase slightly with increasing air apeed.

Figure $4 \mathrm{~b}$ shows ice-fraction results obtained with essentially the same air speed and temperature range as that used in Figure 4a, but with a much lower value of liquidwater content. It is immediately apparent that similar trends are observed: a minimum with respect to air temperature (shifted to $-15^{\circ} \mathrm{C}$ ); and no discernible effect of wind speed. However, it is evident that the lower value of liquid-water content has led to higher ice fractions, the increase ranging from about $10 \%$ at low temperatures to about $15 \%$ at higher temperatures.

It appears that a smaller fraction $\left(f_{\mathrm{w}}\right)$ of the incident water is retained in the ice matrix as the water flux is reduced, the growing ice occupying a greater fraction of the retained mass. Using the macroscopic theory developed later, this trend is not unexpected, but may be influenced by the droplet-size distribution, which was not treated as a controlled experimental variable in the tests reported here; typically, the mean droplet diameter was around $700 \mu \mathrm{m}$ for the higher water flux, but much lower than this for the lower flux (e.g. $300 \mu \mathrm{m})$. A heat balance applied at the accreting surface requires that the latent heat released, minus the warming of the water flux, must be equal to the convective-heat loss: i.e.

$$
\lambda w U f_{\mathrm{i}}-w U c_{\mathrm{p}} \theta=\bar{h} \theta
$$

where $\lambda$ is the latent heat of fusion, $w$ is the liquid-water content, $U$ is the water (air) velocity, $c_{\mathrm{p}}$ is the specific heat of water, $\bar{h}$ is the surface heat-transfer coefficient, and $\theta=T_{\mathrm{i}}-T_{\mathrm{a}}$ is the temperature difference between the ice and the ambient air. Hence

$$
w\left(\lambda f_{\mathrm{i}}-c_{\mathrm{p}} \theta\right)=\bar{h} \theta / U
$$

from which it follows that, if the air temperature and speed are fixed, the two sides of the equation are constant, in which case a decrease in $w$ must be accompanied by an increase in $f_{\mathrm{i}}$. Since the fraction of the water flux subsequently shed $\left(f_{\mathrm{s}}\right)$ was found to be negligible under these conditions, $f_{\mathrm{i}}+f_{\mathrm{w}}=1$, and hence $\left(\partial f_{\mathrm{i}} / \partial w\right)=(\partial I / \partial w)$ is negative, as Figure $4 \mathrm{~b}$ confirms. The increase in this effect with increasing air temperature is evidently attributable to the decreasing relative importance of the water sensible heat as the freezing point is approached. That is, $\partial I / \partial w$ becomes increasingly negative as $T_{\mathrm{a}} \rightarrow 0^{\circ} \mathrm{C}$.

The data in Figure 4 reveal the small and continuous effects of the spray on ice fraction and thus suggest no qualitative behavioural changes over the range of conditions covered. Visual observations, however, indicated that the morphology of the accretion did vary, at least with temperature. For air temperatures close to $0^{\circ} \mathrm{C}$, the accreting surface was highly reflective (glazed), presumably because of the water flowing over it and subsequently shed. Very occasionally, a protuberance would appear on the pebbly surface and grow very much faster than the ice immediately surrounding it. On the other hand, much lower air temperatures produced a mat ice surface, the amount of shed water being much reduced.

It is believed that these appearances signify two different regimes: it is suggested that at higher temperatures $\left(T_{\mathrm{a}} \geqslant-10^{\circ} \mathrm{C}\right)$, ice accretion forms essentially by anisotropic dendritic growth of the ice "front" into supercooled water, while at much lower temperatures $\left(T_{3} \leqslant-15^{\circ} \mathrm{C}\right)$ nucleation continually occurs at new sites in the supercooled water film, growth then being more or less isotropic around the nuclei. The first of these morphologies has been described here as "columnar" to reflect the long grains produced with their $a$-axes presumably aligned with the growth direction; 
the second morphology has been simply described as "mushy" because it had a consistency and structural integrity rather like a thick grey paste about to set. In bending, the columnar ice fractured along well-defined grain boundaries, while the mushy ice showed no such tendencies, being only loosely held together like wet snow or slush. This difference in structure and structural integrity is quite remarkable given the minor variations in ice fraction revealed in Figure 4.

The measured ice thickness was plotted against time with $T_{\mathrm{a}}=-15^{\circ} \mathrm{C}$ for several air speeds. Each set of data appeared to fit the form

$$
x_{\mathrm{i}}=a t+b
$$

where $a$ and $b$ were functions of the prevailing conditions. To test this linear hypothesis, the sets of data were mutually normalized by first referring each set to a single, representative set fitted to the linear form through
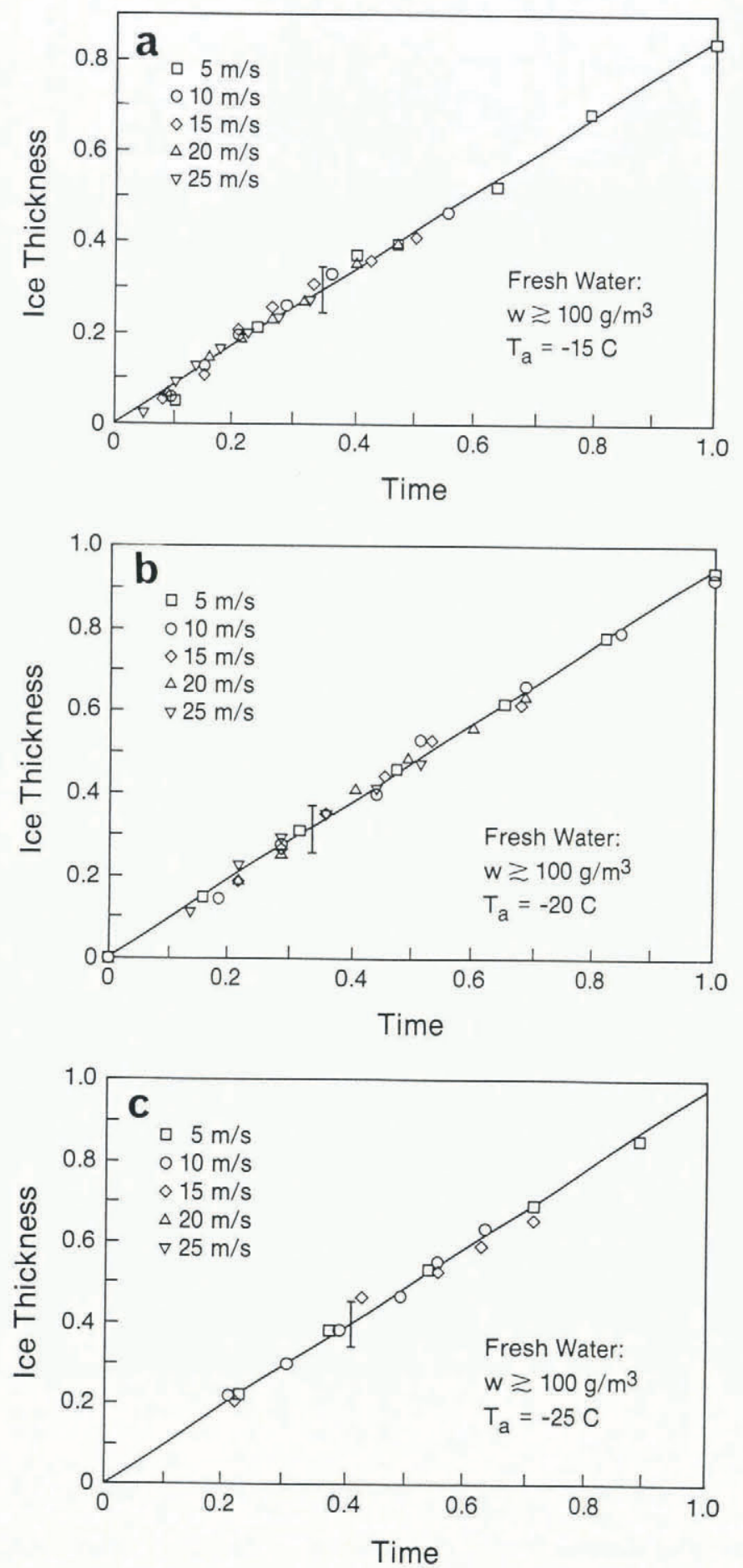

Fig. 5. Fresh-water ice growth: mushy regime (normalized). a. $T_{a}=-15^{\circ} \mathrm{C} ;$ b. $T_{a}=-20^{\circ} \mathrm{C} ;$ c. $T_{a}=-25^{\circ} \mathrm{C}$. regression. In other words, if the latter were expressed, for example, as $x_{\mathrm{i}}(t)=a_{0} t+b_{0}$, any other data set fitting the line $x_{\mathrm{i}}^{\prime}(t)=a_{1} t+b_{1}$, say, would be re-plotted after each data point had been adjusted by $\left(b_{1}-b_{0}\right)+\left(a_{1}-a_{0}\right) t$. The results of these superpositions are shown in Figure 5 a after the physical data were non-dimensionalized by dividing each variable by a representative measure of the range displayed It is evident that the linear form provides an adequate description of the data when $T_{a}=-15^{\circ} \mathrm{C}$. Similar results are shown in Figure $5 \mathrm{~b}$ and $\mathrm{c}$ with $T_{\mathrm{a}}=-20^{\circ} \mathrm{C}$ and $-25^{\circ} \mathrm{C}$, respectively.

With $T_{\mathrm{a}}=-5^{\circ} \mathrm{C}$, the ice thickness was discovered to be a monotonically increasing function of time, concave downward. It was found that

$$
x_{\mathrm{i}}=c \ln (t)+d
$$

fitted the data, which are shown in mutually normalized form in Figure 6a. This behaviour is also evident in Figure
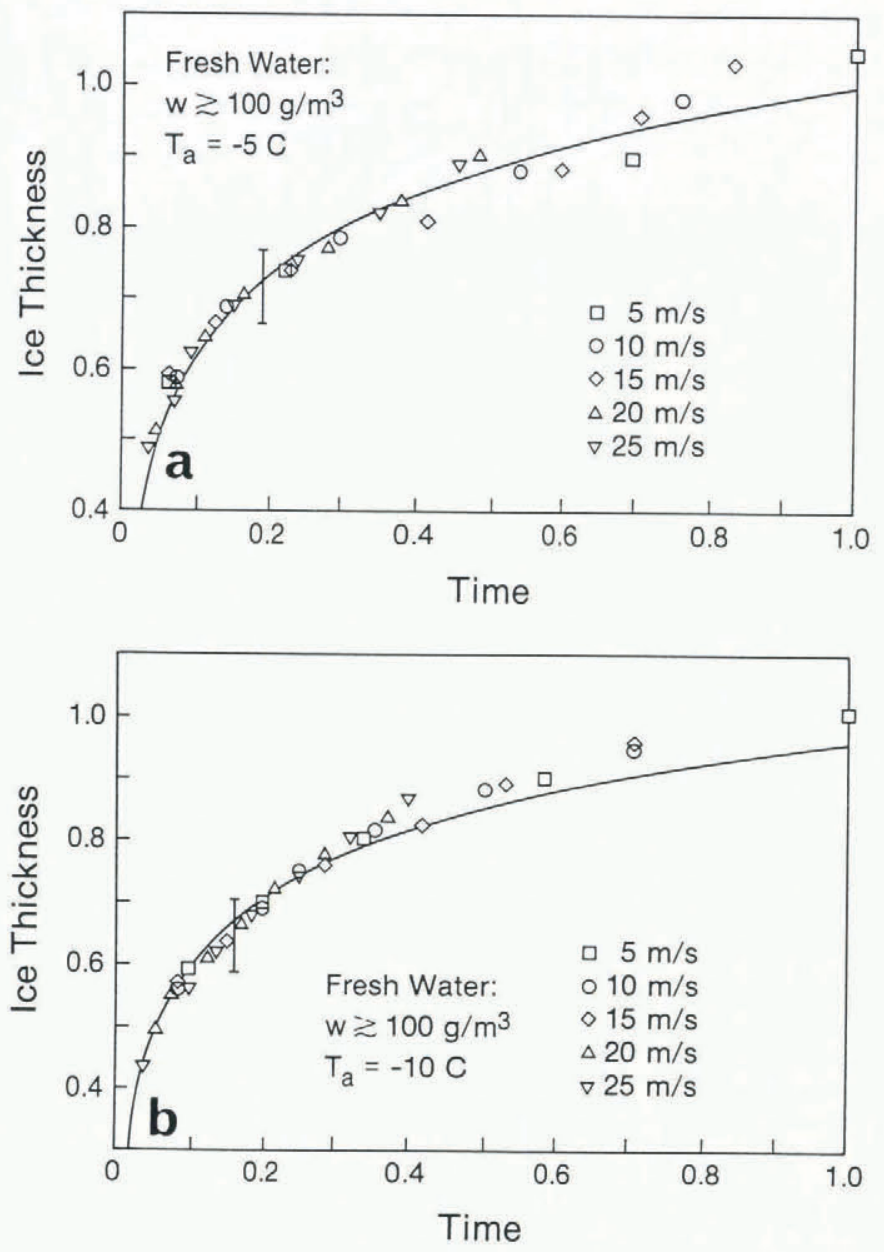

Fig. 6. Fresh-water ice growth: columnar regime (normalized). a. $T_{a}=-5^{\circ} \mathrm{C}:$ b. $T_{a}=-10^{\circ} \mathrm{C}$.

$6 \mathrm{~b}$ for which the air temperature was $-10^{\circ} \mathrm{C}$. The distinct shapes of the ice-growth curves in Figures 5 and 6 are thus in agreement with visual observations, suggesting that the nucleation and growth processes change significantly in the air temperature range $-15^{\circ} \mathrm{C}<T_{3}<-10^{\circ} \mathrm{C}$, although this alteration is masked in the ice-fraction curves.

\section{Salt-water results}

The ice-fraction data for sea-water brine are shown in Figure 7. Comparison between Figures $7 \mathrm{a}$ and $4 \mathrm{a}$, both of which are for a liquid-water content of $100 \mathrm{~g} \mathrm{~m}^{-3}$, reveals two facts: the brine-ice fractions are consistently lower than those for fresh water; and the difference, which is of the order of $10 \%$, increases slightly with an increasing air temperature. The basic shape of the curve remains unaltered. 

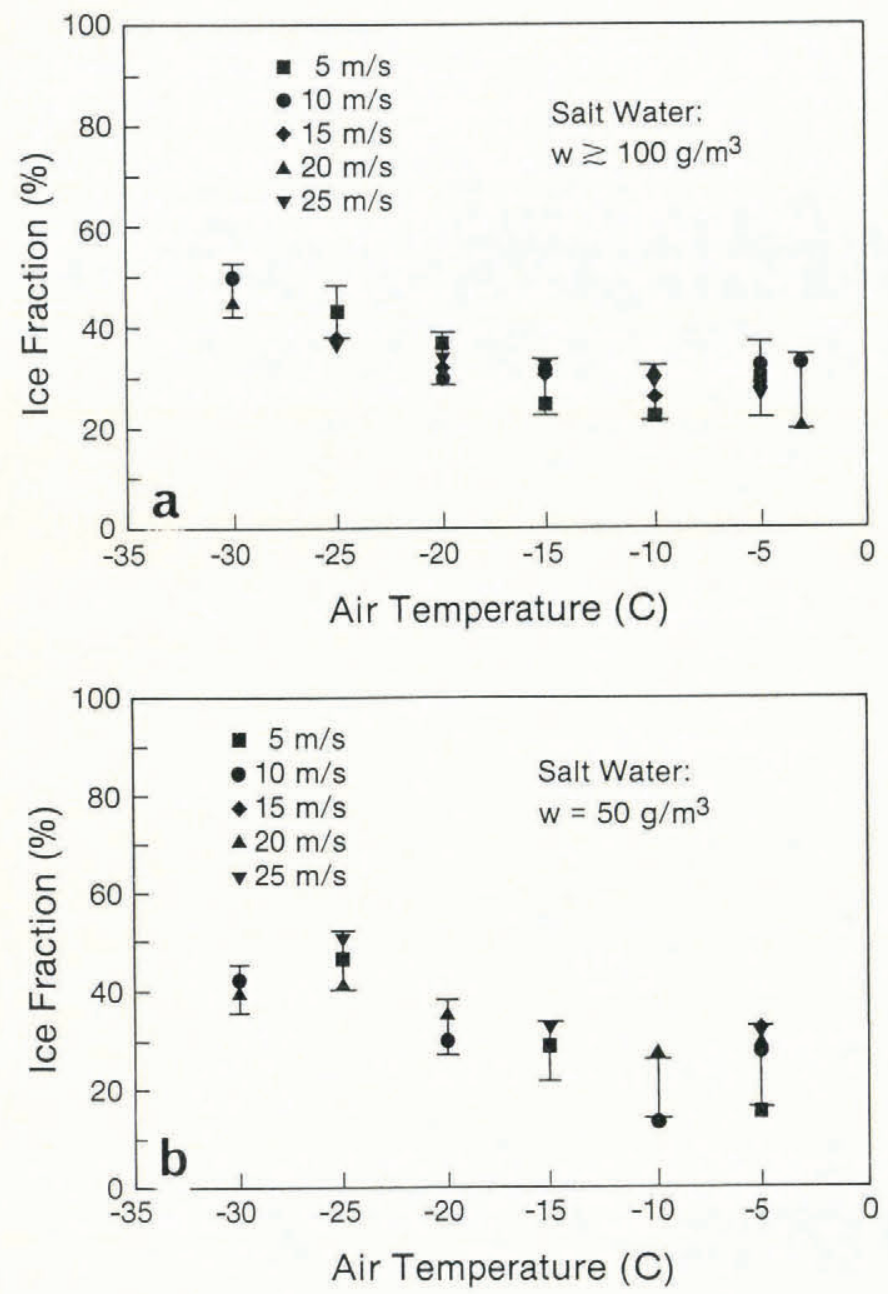

Fig. 7. Salt-water ice fraction as a function of air temperature and speed. a. $\quad w \gtrsim 100 \mathrm{~g} \mathrm{~m}^{-3} ; \quad b$. $w=50 \mathrm{~g} \mathrm{~m}^{-3}$.

Given the behaviour of fresh-water accretion discussed above, this behaviour of salt-water accretion is not too surprising. The effect of air speed is again undiscernible. The increase in unfrozen water content is presumably caused by freezing-point depression resulting from salt rejection at the ice-water interface. The effect of salinity is evidently greater at higher air temperatures, but whether this is attributable to temperature alone or to a change from a mushy regime to a columnar regime is uncertain. Figure $7 \mathrm{~b}$ reveals that lowering the liquid-water content to $50 \mathrm{~g} \mathrm{~m}^{-3}$ produced no effect on ice fraction. This fact stands in contrast to the effect of lowering the liquid-water content of a fresh-water spray, and again suggests the role of freeze concentration in interstitial water is to limit the growth of the ice in the matrix.

In the mushy regime, the growth of saline ice was found to be linear, as anticipated. Typical growth data are shown in Figure 8. They reveal that liquid-water content variations in the range $50-120 \mathrm{~g} \mathrm{~m}^{-3}$ produce no significant effect on growth rate. Also shown in Figure 8 are fresh-water data obtained under the same conditions. It is evident that the salinity of simulated sea-water has a negligible effect on growth rate, at least when $w=$ $100 \mathrm{~g} \mathrm{~m}^{-3}$. Growth data in the columnar regime were found to be very similar to the fresh-water data discussed earlier. In particular, growth rates were significantly less than those observed in the mushy-regime, and were logarithmic in form. Figure 9 provides some typical results.

\section{Physical theory}

The above observations have led to the suggestion that a mushy growth regime persisted for air temperatures less than an upper limit between $-10^{\circ}$ and $-15^{\circ} \mathrm{C}$. Although no crystallographic studies were made, it would be necessary to undertake these to confirm, or deny, the grain structure and

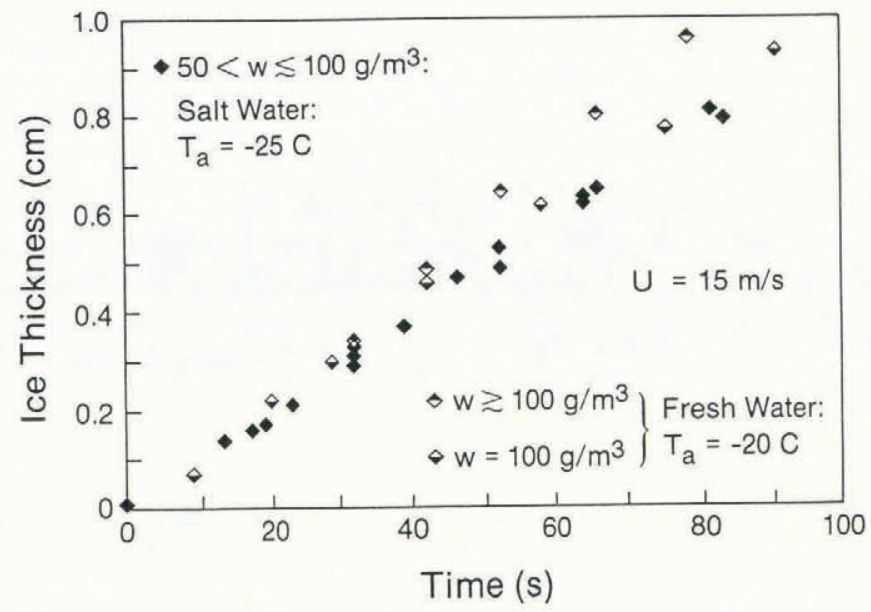

Fig. 8. Ice-growth comparison.
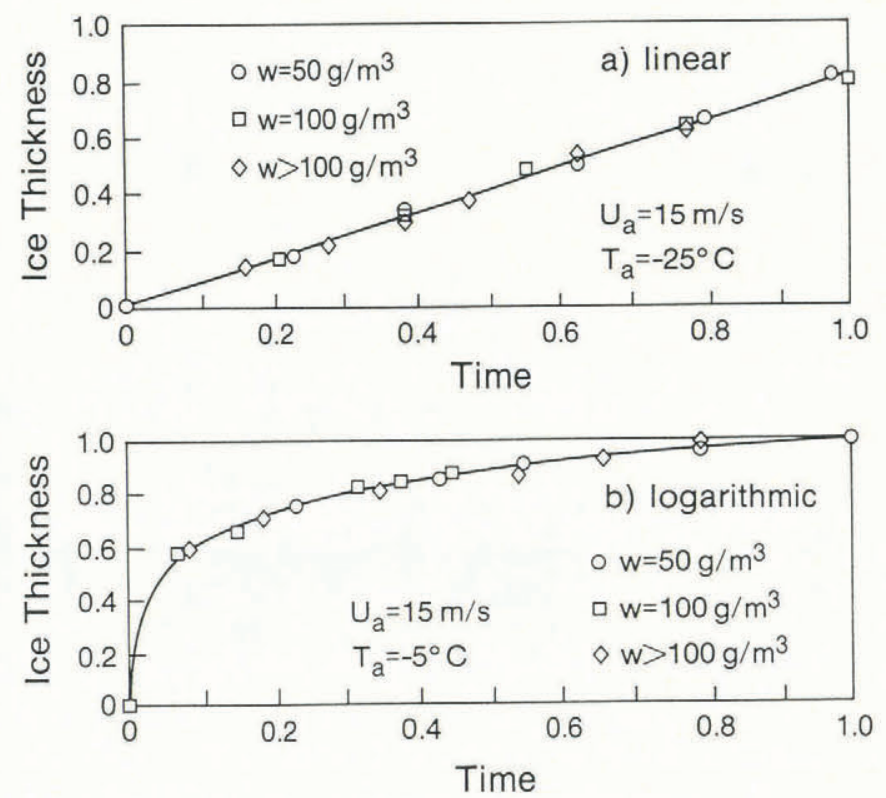

Fig. 9. Typical salt-water growth curves. $a$. Linear; $b$. Logarithmic.

orientation suggested. The softness of this accretion indicates that it would be easy to remove the substrate provided the accretion temperature remained at the equilibrium freezing value. If the interstitial water should subsequently freeze, the resulting ice would be fine-grained and essentially isotropic.

The nucleation and growth processes in mushy accretion are not clearly understood; in particular, it is not known if nuclei first appear in the spray or in the water film on the accretion surface. The ice-front velocity is much lower than $a$-axis velocities observed for water supercoolings (based on the air temperature) characteristic of the mushy regime, and this suggests that a simple, linear dendritic theory would not apply at the microscopic level. Since the shed-water fraction is negligible under these conditions, it appears that the spray water either freezes or is retained interstitially. The Stefan number (Ste) in the range studied was less than, but not very much less than, 1.0 and therefore the fraction of the spray actually freezing would raise the local film temperature significantly above the air temperature. The local supercooling would thus be much smaller than that indicated by the air temperature, and the crystalline-growth velocity would be reduced accordingly. This explanation suggests an ice fraction which increases with a decreasing air temperature (increasing Stefan number), as observed above. It also implies that air speed should have little effect, as noted.

Macroscopically, the situation may be described in general by a mass balance,

$$
w U=w U\left(f_{\mathrm{i}}+f_{\mathrm{w}}+f_{\mathrm{S}}\right)
$$


or, if $x_{\mathrm{i}}$ is the accretion thickness attained in time $t$,

$$
w U\left(1-f_{\mathrm{S}}\right)=\bar{\rho} \frac{\mathrm{d} x_{\mathrm{i}}}{\mathrm{d} t}
$$

where $\bar{\rho}$ is the mean accretion density. This must be accompanied by the heat balance given in Equation (1). Hence,

$$
\lambda w U\left(1-f_{\mathrm{S}}\right)=\frac{\bar{h} \theta}{I-\text { Ste }}+\frac{\lambda w U f_{\mathrm{S}} \text { Ste }}{I-\text { Ste }}
$$

where Ste $=c_{p} \theta / \lambda$, is the ratio of the sensible and latent heats (Lock, 1969). This reduces to

$$
\bar{\rho} \lambda \frac{\mathrm{d} x_{\mathrm{i}}}{\mathrm{d} t}=\frac{\bar{h} \theta}{I-\text { Ste }}
$$

using Equation (2) and assuming

$$
\frac{f_{\mathrm{S}} \text { Ste }}{I-\text { Ste }} \ll 1-f_{\mathrm{S}} \text {. }
$$

This latter inequality, will be satisfied if $f_{\mathrm{S}} \ll 1$ and Ste $\leqslant I-$ Ste, i.e. the ice fraction is greater than the order of twice the Stefan number or $I \geqslant 0(2 \mathrm{Ste})$. Typically, it was found that $I=0(2 \mathrm{Ste})$ and $f_{\mathrm{S}} \ll 1$ in the mushy regime* and hence Equation (4) is a satisfactory approximation from which it follows that

$$
x_{\mathrm{i}}=\frac{\bar{h} \theta t}{\bar{\rho} \lambda(I-\text { Ste })}
$$

if the substrate is initially free of ice.

It is immediately obvious that Equation (5) has the linear form characteristic of mushy growth provided that $\bar{h}$, $\theta$, Ste, and $I$ are fixed. The ice-fraction results indicate that $I$ is a weak function of air speed and temperature, but $\bar{h}$, which is determined principally by the Reynolds number of the substrate (Kays, 1966), is a function of air speed while Ste, and of course $\theta$, are functions of air temperature. It is thus evident that ice-front velocity will increase monotonically with both air speed and air temperature. These expectations were borne out by the raw data plots of $x_{\mathrm{i}}$ versus $t$. As a specific example for fresh water, it was found that for $T_{\mathrm{a}}=-20^{\circ} \mathrm{C}$ and $U=5 \mathrm{~m} \mathrm{~s}^{-1}$ (giving $I=0.37$ ), the predicted value of growth velocity was $0.029 \mathrm{~mm} \mathrm{~s}^{-1}$ while the measured value was $0.03 \mathrm{~mm} \mathrm{~s}^{-1}$.

In the columnar regime, this linear growth model fails, as the above data have demonstrated. The logarithmic form could be generated from Equation (4) if the right-hand side was inversely proportional to $t$, but such an explanation appears to be facile. Supplementary experiments verified that $I$ was independent of time thus leaving $\bar{h}$ as the only variable in the equation potentially capable of transience; however, there is no particular reason to believe that $\bar{h}$ would decrease so dramatically (with surface roughness, for example). Nor is there any reason to believe that reductions in $\vec{h}$ alone are the cause of the ice-front velocities being significantly less than those measured in the mushy regime. It is suggested that the lower front velocities in the columnar regime are caused principally by reductions in $\theta$. It is worth noting that the assumption of $f_{\mathrm{S}} \ll 1$ implicit in Equation (4) may not be valid in the columnar regime; if not, the growth velocity would be increased slightly by the second term on the right-hand side of Equation (3).

Attempts to predict the growth rate for saline ice were unsuccessful. In the columnar regime this was not surprising but the lack of agreement in the mushy regime led to a reconsideration of the physical model. As an alternative, it was assumed that freezing took place over a temperature range: that is

* No attempt was made to measure $f_{S}$; the absence of shed water is based on simple, visual observation.

$$
\frac{\mathrm{d} x_{\mathrm{i}}}{\mathrm{d} t}=\frac{\bar{h} \theta}{\bar{\rho} \int_{0}^{\theta} c_{\mathrm{p}}(\theta) \mathrm{d} \theta}
$$

where $c_{\mathrm{p}}(\theta)$ represents the freezing mixture. This expression generated ice-front velocities which were much lower than those observed, while the earlier macroscopic model predicted higher velocities. The truth evidently lies somewhere in between.

\section{CONCLUSIONS}

The growth of spongy ice near the forward stagnation point of a disc situated in a dense, supercooled water spray has been investigated experimentally for a wide range of air speeds and temperatures. Measurements of ice fraction and ice-front velocity are presented for sprays of fresh and saline water, with liquid-water contents varying in the range $10-120 \mathrm{~g} \mathrm{~m}^{-3}$. Spray-droplet diameter was not controlled but remained in the order of $5 \times 10^{2} \mu \mathrm{m}$ for the results presented.

It was found that the ice fraction did not vary greatly over the range of conditions covered. In particular, no discernible effect of wind speed was observed within the experimental error of $\pm 5 \%$. The effect of air temperature was found to be slight and was characterized by a shallow minimum located in the temperature range $-10^{\circ}$ to $-15^{\circ} \mathrm{C}$. While the increase of ice fraction accompanying decreasing air temperatures is expected to continue below the range explored here, it is not certain that the upward concavity would extend into the temperature range $-5^{\circ} \mathrm{C}$ to $T_{\mathrm{i}}$. The fragility of the ice accretion in this temperature range makes experiments very difficult to undertake for all but the very lowest air speeds. It is speculated that the ice fraction would decrease to zero as $T_{\mathrm{i}}$ is approached.

The minimum in the ice fraction evidently serves to distinguish between morphological regimes. Above $T_{\mathrm{a}}=$ $-10^{\circ} \mathrm{C}$, the accretion is "columnar" and appears to grow dendritically into the reflecting water film observed on the surface. Below $-15^{\circ} \mathrm{C}$, growth is believed to occur on many randomly distributed nuclei which produce a finer, and less cohesive, "mushy" ice structure. Two regimes were distinguishable in the ice-front growth curves. In the mushy regime, growth was found to be linear, in agreement with macroscopic theory. In the columnar regime, growth was slower and logarithmic, but no theoretical explanation of this behaviour has yet been advanced.

The effect of salinity, at a level corresponding to sea-water, was also investigated. It was found that, although the ice fractions were lowered slightly, the dependence on air speed and temperature remained essentially unchanged. However, the presence of sea salt did produce reductions in the ice-front velocity in both the columnar and mushy regimes. This is believed to result from increases in the shed water in which freeze concentration had lowered its equilibrium freezing temperature enough to prevent freezing during run-back. An attempt was made to model the saline accretion as a binary mixture with a freezing-temperature range. This predicted growth velocities beneath the observed values, while the pure water model predicted higher values.

It is evident that the theoretical prediction of ice-front velocities needs further development. A single-component macroscopic model appears to be satisfactory for mushy growth from fresh water, albeit in the absence of a detailed description of nucleation and embryo growth. However, in its present form it is not applicable to the columnar regime, and it does not readily accommodate the effects of dissolved salt.

\section{ACKNOWLEDGEMENTS}

This work was conducted under the auspices of the Natural Sciences and Engineering Research Council of Canada to whom we are grateful. We also wish to thank E. Standing for assistance in the preliminary work, and to extend our gratitude to the Department of Mechanical Engineering technicians, Mr B. Cielin in particular. 


\section{REFERENCES}

Brownscombe, J.L. and J. Hallett. 1967. Experimental and field studies of precipitation particles formed by the freezing of supercooled water. Q. J. R. Meteorol. Soc., 93(398), 455-473.

Foy, C. Unpublished. The design, instrumentation and performance of a refrigerated marine icing wind tunnel. (M.Sc. thesis, University of Alberta, 1988.)

Fraser, D., C.K. Rush, and D. Baxter. 1953. Thermodynamic limitations of ice accretion instruments. Bull. Am. Meteorol. Soc., 34(4), 146-154.

Gates, E.M., R. Narten, E.P. Lozowski, and L. Makkonen. 1986. Marine icing and spongy ice. In International Association for Hydraulic Research. 8th International Symposium on Ice, Iowa City, August 18-22, 1986. Vol. 2. Iowa City, IA, University of Iowa. Institute of Hydraulic Research, 153-163.

Kays, W.M. 1966. Convective heat and mass transfer. New York, McGraw-Hill.

Knight, C.A. 1968. On the mechanism of spongy hailstone growth. J. Atmos. Sci., 25(3), 440-444.

Knight, C.A. and N.C. Knight. 1968a. Spongy hailstone growth criteria. I. Orientation fabrics. J. Atmos. Sci., $25(3), 445-452$.
Knight, C.A. and N.C. Knight. 1968b. Spongy hailstone growth criteria. II. Microstructures. J. Atmos. Sci., 25(3), 453-459.

Lindenmeyer, C.S. Unpublished. The solidification of supercooled aqueous solutions. (Ph.D. thesis, Harvard University, 1959.)

List, R. 1959. The growth of ice-water composition in an experimental tunnel. Helv. Phys. Acta, 32, 293-296.

Lock, G.S.H. 1969. On the use of asymptotic solutions to plane ice-water problems. J. Glaciol., 8(53), 285-300.

Macklin, W.C. 1961. Accretion in mixed clouds. Q. J. $R$. Meteorol. Soc., 87, 413-424.

Macklin, W.C. and B.F. Ryan. 1965. The structure of ice grown in bulk supercooled water. J. Atmos. Sci., 22(4), 452-459.

Makkonen, L. 1987. Salinity and growth rate of ice formed by sea spray. Cold Reg. Sci. Technol., 14(2), 163-171.

Pruppacher, H.R. 1967. Growth modes of ice crystals in supercooled water and aqueous solutions. J. Glaciol., 6(47), 651-662.

Szilder, K. and E.P. Lozowski. 1989. A time-dependent thermodynamic model of the build-up of sea-ice platforms. J. Glaciol., 35(120), 169-178. 